\title{
Regulated differentiation of WERI-Rb-1 cells into retinal neuron-like cells
}

\author{
YING LIU ${ }^{1}$, HUILING HU ${ }^{2}$, MEIXIN LIANG ${ }^{1}$, YUNFAN XIONG $^{3}, \mathrm{KANG} \mathrm{LI}^{1}$, MENGFEI CHEN $^{4}$, ZHIGANG FAN $^{1}$, \\ XIELAN KUANG ${ }^{1}$, FEI DENG ${ }^{1}$, XIAOHONG LIU ${ }^{5}, \mathrm{CHAOCHAO} \mathrm{XU}^{1}, \mathrm{KAIJING} \mathrm{LI}^{1}$ and JIAN GE${ }^{1}$ \\ ${ }^{1}$ State Key Laboratory of Ophthalmology, Zhongshan Ophthalmic Center, Sun Yat-sen University, Guangzhou, \\ Guangdong 510060; ${ }^{2}$ Shenzhen Key Laboratory of Ophthalmology, Shenzhen Eye Hospital, Shenzhen, Guangdong 518034; \\ ${ }^{3}$ The First Affiliated Hospital of Kunming Medical University, Kunming, Yunnan 650000, P.R. China; \\ ${ }^{4}$ Department of Otolaryngology-Head and Neck Surgery, Johns Hopkins University School of Medicine, \\ Baltimore, MD 21087, USA; ${ }^{5}$ Department of Ophthalmology, Shanghai Jiaotong University \\ Affiliated Sixth People's Hospital, Shanghai 200233, P.R. China
}

Received February 17, 2017; Accepted August 8, 2017

DOI: $10.3892 / \mathrm{ijmm} .2017 .3102$

\begin{abstract}
The encouraging response and improved survival of acute promyelocytic leukemia patients following retinoic acid treatment has rendered differentiation therapy an attractive option in cancer treatment. Given that terminal differentiation represents a considerable barrier in retinoblastoma tumorigenesis and that retinoblastoma has a significantly higher spontaneous degeneration rate compared with other tumors (1,000-fold change), differentiation therapy represents a promising alternative in the treatment of retinoblastoma. However, the full differentiation potential of retinoblastoma still unknown. The present study was designed to investigate the extend differentiation of the classical retinoblastoma cell line WERI-Rb-1 (W-RBCs). Several critical cell signaling pathways and key genes related to cell proliferation and differentiation were comprehensively regulated to control the fate of W-RBCs. Various strategies were applied to optimize simple and time-saving methods to induce W-RBCs into different types of retinal neuron-like cells (RNLCs) in vitro. Further, the tumorigenesis of these differentiated W-RBCs was tested in nude mice in vivo. W-RBCs were found to inherently express both retinal progenitor cell- and embryonic stem cell-related genes or proteins. Moreover, the addition of antagonists of critical cell signals (Wnt, Nodal, BMP4 and Notch), even without atonal bHLH transcription factor 7 gene transfection, could directly induce W-RBCs into RNLCs, and especially into photoreceptor-like and retinal ganglion-like
\end{abstract}

Correspondence to: Dr Jian Ge, State Key Laboratory of Ophthalmology, Zhongshan Ophthalmic Center, Sun Yat-sen University, 54S Xian Lie Road, Guangzhou, Guangdong 510060, P.R. China

E-mail: gejian@mail.sysu.edu.cn

Key words: retinoblastoma, differentiation, retinal neuron, cell signal cells. Interestingly, the differentiated cells showed remarkably poorer tumorigenesis in vivo. These findings may offer new insights on the oriented differentiation of W-RBCs into RNLCs with low tumorigenicity and provide potential targets for retinoblastoma differentiation therapy.

\section{Introduction}

Retinoblastoma is the most common intraocular malignancy $(1,2)$. Although early tumor detection and novel coordinate therapies contribute to significantly improved survival (80-97\%) and eye salvage now, the chemoresistant and toxicity of chemotherapy and the secondary tumor risk of radiation all necessitate innovative treatment strategies to combat the initiation and progression of retinoblastoma.

The revolutionary treatment of acute promyelocytic leukemia patients through retinoic acid-induced differentiation and their subsequent improved survival have rendered differentiation therapy an attractive option in cancer treatment $(3,4)$. Retinoblastoma was originally thought to be caused by the escape of cell apoptosis (5). However, a previous transgenic mice study indicates terminal differentiation, rather than apoptosis, to be the most important barrier in retinoblastoma tumorigenesis (6). Further, clinical evidence revealed that the spontaneous regression rate of retinoblastoma (1.8-3.2\%) is 1,000 -fold higher than in other tumors (7-10), the mechanism of this phenomenon has not been convinced, but may have some relationship with cell differentiation $(10,11)$. All render retinoblastoma as a unique tumor suitable for differentiation therapy.

Retinoblastoma cells have similar characteristics with retinal progenitor cells (RPCs). Some studies use chemical agents, such as retinoids, pyruvate and arsenic $(12,13)$, to induce retinoblastoma differentiate into neuron-like and glia-like cells; however, the side effects, including headaches, drug resistance, and toxicity (14-16), have been reported with these agents. All necessitate optimized agents for retinoblastoma differentiation. 
Cell cycle re-entry and terminal differentiation disorders transform normal retinal stem cells into malignant retinoblastoma cells (17). Thus, specific cell signals related to both cell growth and differentiation would be critical to regulate retinoblastoma to differentiate into retinal neurons. Several intrinsic cell signals, including Wnt, Nodal, bone morphogenetic protein (BMP), Notch and fibroblast growth factor (FGF) signals, are promising candidates. Activation of Wnt or Nodal signals can maintain retinal progenitor cells (RPCs) in an uncommitted state. Inhibition of these signals induces embryonic stem cells (ESCs) (18-20) or induced pluripotent stem cells (iPSCs) (21) into photoreceptors. Basic fibroblast growth factor (bFGF) enhance photoreceptors and neurons from RPCs (22) and neural stem cells (23). Besides the unique signal, the signaling cross-talk effect should also be considered. Convincing evidence has emerged that zebrafish brain resulted from the triple inhibition of Wnt, Nodal and BMP signaling. The early development of retinal requires for inhibition of BMP and activation of FGF signaling. Furthermore, inhibition of Wnt, Nodal, BMP and Notch signals together with atonal bHLH transcription factor 7 (ATOH7) gene overexpression could generate RGLCs from iPSCs (21). For retinoblastoma, activating Wnt signal stimulates tumor stem cell proliferation (23-26), whereas inhibiting the Notch (27) and BMP signal $(28,29)$ suppresses tumor growth and activates apoptosis, respectively. Nevertheless, retinoblastoma studies mainly focus on cell proliferation and single signal effects, with none reporting on the differentiation through multi-signal regulation.

The present study aimed for retinoblastoma differentiation through the targeted regulation of several critical cell signaling and key genes. It was identified that the classic retinoblastoma cell line WERI-Rb-1 cells (W-RBCs) could be directly induced into retinal neuron-like cells (RNLCs). Importantly, the differentiated cells show remarkably poorer tumorigenicity in vivo. Collectively, the present study provides optimized strategies for regulated WERI-Rb1 cell differentiation and offers potential targets for the retinoblastoma differentiation therapy.

\section{Materials and methods}

Tissue collection. Two human embryonic neural retinas at the eighth to ninth week of gestation were donated from legal therapeutic abortions in the Third Affiliated Hospital, Sun Yat-Sen University (Guangzhou, China). Informed consent for tissue donation was obtained before acquisition of the tissue. All the samples were collected under the auspices of the protocols for the institutional review boards at Zhongshan Ophthalmic Center and the Third Affiliated Hospital, Sun Yat-Sen University. The study was approved by the Ethics Committee of Zhongshan Ophthalmic Center and the Third Affiliated Hospital, Sun Yat-Sen University.

Cell isolation and culture. The human retinoblastoma cell line WERI-Rb-1 (2011; American Type Culture Collection, Manassas, VA, USA) were cultured in RPMI-1640 medium (HyClone; GE Healthcare Life Sciences Chalfont, UK) with $10 \%$ fetal bovine serum (Gibco; Thermo Fisher Scientific, Inc., Waltham, MA, USA). Primary human RPCs were isolated from human embryonic neural retinas and cultured, as previously described $(30,31)$.

Retinal neuron-like cell differentiation. To develop an effective procedure to induce W-RBCs into RNLCs, two protocols were adopted according to $\operatorname{RPC}(22), \operatorname{ESC}(18,20)$ and iPSC $(21,32)$ differentiation, with some modifications: the first protocol involved a two-step process, with priming and differentiation, whereas the second involved only one step, with either priming or differentiation. Briefly, single W-RBCs, with the density of $2 \times 10^{4}$ cells $/ \mathrm{ml}$, were placed in 24 -well plates pre-coated with $0.1 \mathrm{mg} / \mathrm{ml}$ poly-D-lysine (PDL) for $24 \mathrm{~h}$ and $5 \mu \mathrm{g} / \mathrm{ml}$ laminin (both from Sigma-Aldrich; Merck KGaA, Darmstadt, Germany) for $1 \mathrm{~h}$. The W-RBCs were primed in 'basic medium': DMEM/F12, 15\% fetal bovine serum (FBS), $0.1 \mathrm{mM}$ non-essential amino acids, $10 \mathrm{ng} / \mathrm{ml} \mathrm{bFGF}, 0.1 \mathrm{mM}$ 2-mercaptoethanol, 2\% B27, and 1\% N-2 supplement (all from Gibco; Thermo Fisher Scientific, Inc.). A total of 10 days later, the medium was replaced with 'neural medium' (Neurobasal, $2 \%$ B27, $1 \% \mathrm{~N}-2$ supplement, 5\% FBS, $0.1 \mathrm{mM}$ non-essential amino acids and $2 \mathrm{mM}$ L-glutamine; all from Gibco; Thermo Fisher Scientific, Inc.) for a further 10 days of differentiation. The cytokines Dickkopf-related protein 1 (Dkk-1, $100 \mathrm{ng} / \mathrm{ml})$ and Lefty-A (500 ng/ml, both from R\&D Systems, Inc., Minneapolis, MN, USA) [Dkk-1+Lefty-A (DL)] were used in the study. The cells were split into six groups: groups 1 (DL-20d) and group 2 (N2-Neural-20d) were subjected to a twostep process with or without DL. Groups 3-6 were subjected to a one-step process for 10 days: groups 3 (DL-N2-10d) and group 4 (N2-10d) were cultured in basic medium with or without DL. Group 5 (DL-Neural-10d) was cultured in neural medium containing DL and group 6 (Neural-10d) was cultured in neural medium only (Fig. 1A).

Retinal ganglion-like cell (RGLC) generation. Single W-RBCs $\left(2 \times 10^{4}\right.$ cells $\left./ \mathrm{ml}\right)$ were seeded onto PDL and laminin-coated 24-well plates and then primed in basic medium, with the addition of Dkk-1 (100 ng/ml), Lefty-A $(500 \mathrm{ng} / \mathrm{ml})$ and Noggin (100 ng/ml; PeproTech, Inc., Rocky Hill, NJ, USA) [DKK-1+Lefty-A+Noggin (DLN)] p $p M V-A T O H 7$ expression plasmids (Vector Gene Technology Co., Ltd., Beijing, China) were then transfected into the cells at room temperature (RT) using X-treme GENE HP DNA Transfection reagent (Roche Diagnostics $\mathrm{GmbH}$, Basel, Switzerland). Following $24 \mathrm{~h}$ of transfection, the medium was changed, and a neural medium containing DLN and $10 \mu \mathrm{M}$ N-[N-(3,5difluorophenacetyl)-L-alanyl]-S-phenylglycine t-butyl ester (DAPT; Merck KGaA, Darmstadt, Germany) [DKK-1+LeftyA+Noggin+DAPT (DLND)] was added for further differentiation. Given the time-dependent distribution of retinal cell development, the cells were split into short- (10 days) and long-period (20 days) induction groups. In the 10-day induction groups, group 1 (DLNAD-10d) was induced by 3 days of priming with DLN and 7 days of differentiation with DLND. The ATOH7 gene was transfected into the cells on the third day. Group 2 (DLN-N2-10d) was cultured only in the basic medium with DLN and without gene transfection. Group 3 (DLNAD-Neural-10d) was similar to group 1, but the medium was replaced with neural medium). Group 4 (N2-TR-10d) and group 5 (Neural-TR-10d) were cultured in basic and neural 
A
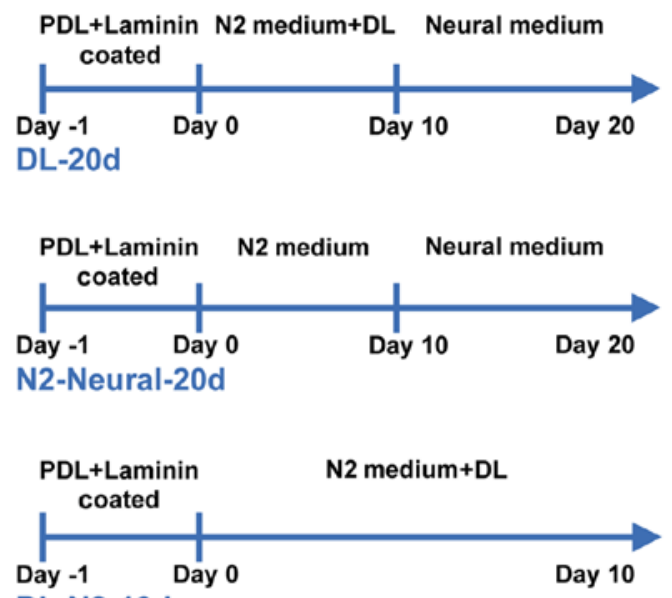

DL-N2-10d
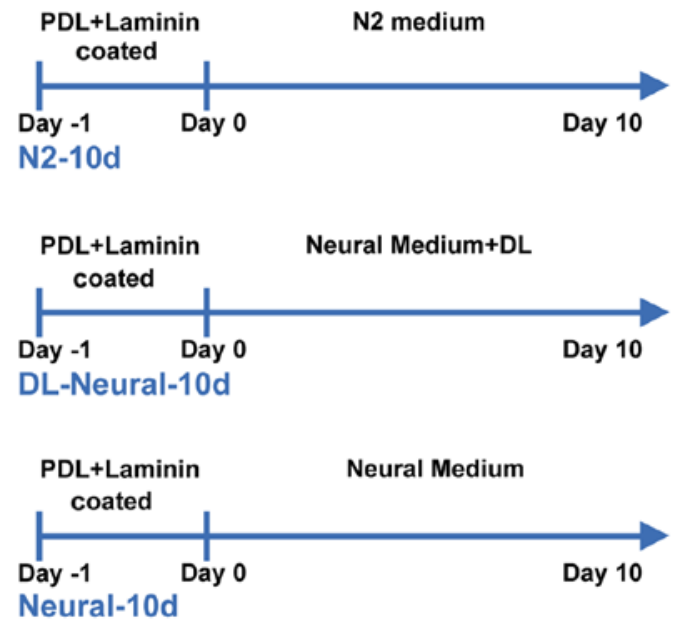

B
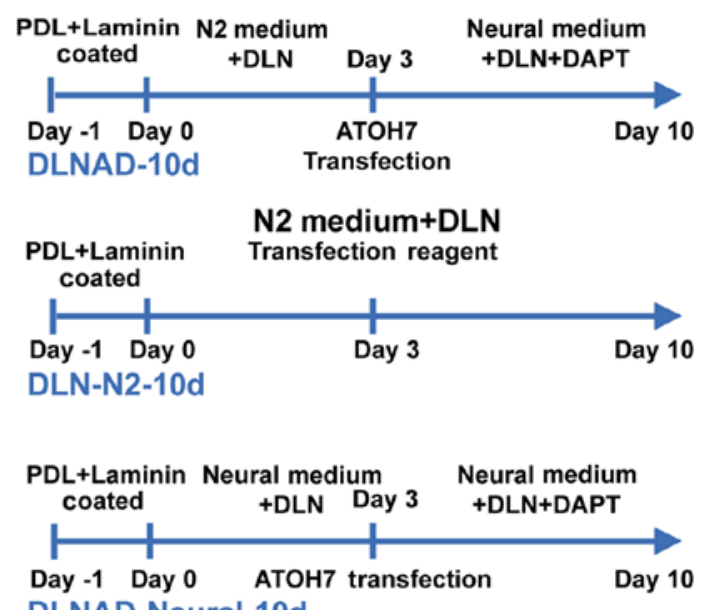

DLNAD-Neural-10d
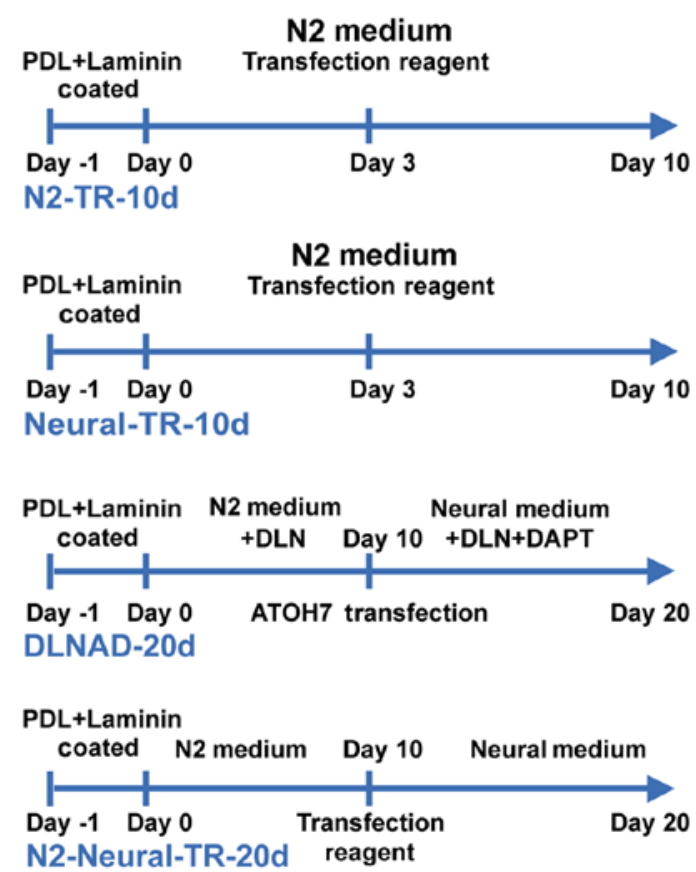

Figure 1. Schematic representation of the WERI-Rb-1 cell induction protocols. (A) Six groups of retinal neuron-like cell differentiation. (B) Seven groups of retinal ganglion-like cell induction. PDL, poly-D-lysine; DLN, Dkk-1 + Lefty-A + Noggin.

medium, respectively, with a blank transfection reagent added on the third day at room temperature. In the 20-day differentiation groups, group 6 (DLNAD-20d) underwent 10 days of priming with DLN and 10 days of differentiation with DLND, and the $A T O H 7$ gene was transfected on the tenth day. Treatment of group 7 (N2-Neural-TR-20d) excluded DLND from the induction system, yet the blank transfection reagent was added on the tenth day at room temperature (Fig. 1B)

Reverse transcription-polymerase chain reaction ( $R T-P C R)$ and quantitative PCR ( $q P C R)$. Total RNA was extracted from cells using TRIzol reagent (Ambion; Thermo Fisher Scientific, Inc.) according to the manufacturer's instructions and then treated with DNase I (Sigma-Aldrich; Merck KGaA) to remove any genomic DNA contamination. cDNA synthesis from $3 \mu \mathrm{g}$ total RNA was conducted with a second-strand cDNA synthesis kit (PrimeScript ${ }^{\mathrm{TM}}$ RT Master Mix; Takara Bio, Inc., Otsu, Japan). For analysis, 100-200 ng of cDNA was ampli- fied with a master mix (Premix Taq ${ }^{\mathrm{TM}}, \mathrm{Ex}^{\mathrm{Ta}} \mathrm{Taq}^{\mathrm{TM}}$ version 2.0 plus dye; Takara Bio, Inc.) and a PCR system (TProfessional Thermocycler; Biometra GmbH, Göttingen, Germany). For quantitative analysis, the cDNA samples were amplified with the Roche LightCycler ${ }^{\circledR} 480$ system (Roche Diagnostics $\mathrm{GmbH}$ ), and the transcripts were quantified using an RT-PCR kit (PrimeScript ${ }^{\mathrm{TM}}$ RT Master Mix; Takara Bio, Inc.). The quantification method is the same as the previously described method (33). Human $\beta$-actin was used as a housekeeping gene to calculate the relative mRNA expression. The primer sequences are listed in Table I.

Western blot analysis. W-RBCs, RNLCs and RGLCs were lysed in radioimmunoprecipitation assay buffer containing a protease inhibitor cocktail (Sigma-Aldrich; Merck KGaA). Total protein was extracted by centrifuging $(12,000 \mathrm{rpm})$ at $4{ }^{\circ} \mathrm{C}$ for $15 \mathrm{~min}$. The protein was quantified with the BCA kit (Boster, Wuhan, China). A total of $30 \mu \mathrm{g}$ protein 
Table I. Primer sequences used in reverse transcription-PCR and quantitative PCR.

\begin{tabular}{|c|c|}
\hline Gene name & Primer sequence $\left(5^{\prime} \rightarrow 3^{\prime}\right)$ \\
\hline NES & $\begin{array}{l}\text { F: GCAGCACTCTTAACTTACGATC } \\
\text { R:GTCACCTCCATTAGCCACA }\end{array}$ \\
\hline CRX & $\begin{array}{l}\text { F: GAAAGCAACCCGAACC } \\
\text { R:AGAATGGCGTGAACCC }\end{array}$ \\
\hline PROM1 & $\begin{array}{l}\text { F: AGTGGCATCGTGCAAACCTG } \\
\text { R:CTCCGAATCCATTCGACGATA }\end{array}$ \\
\hline BMI1 & $\begin{array}{l}\text { F: CTGCAGCTCGCTTCAAGATG } \\
\text { R:TTAGCTCAGTGATCTTGATTCTCG }\end{array}$ \\
\hline MKI67 & $\begin{array}{l}\text { F: CCATATGCCTGTGGAGTGGAA } \\
\text { R:CCACCCTTAGCGTGCTCTTGA }\end{array}$ \\
\hline PRPH2 & $\begin{array}{l}\text { F: CTGCTCAAAGCCCAAACC } \\
\text { R:TCAAATGTGAAACTCAGACCCT }\end{array}$ \\
\hline OPN1LW & $\begin{array}{l}\text { F: CCCACTCGCTATCATCATGCT } \\
\text { R:CAGTACGCAAAGATCATCACCA }\end{array}$ \\
\hline RCVRN & $\begin{array}{l}\text { F: AAGCGAGCCGAGAAGAT } \\
\text { R:TCAGTTTGGCAGGGAGC }\end{array}$ \\
\hline NEUROD1 & $\begin{array}{l}\text { F: GGATGACGATCAAAAGCCCAA } \\
\text { R:GCGTCTTAGAATAGCAAGGCA }\end{array}$ \\
\hline GFAP & $\begin{array}{l}\text { F: ACGCCAGGCTCTCTGCTTTA } \\
\text { R:GCGGTCCTGAGGGAAGAATC }\end{array}$ \\
\hline ROM1 & $\begin{array}{l}\text { F: GCTGGCTGTCACCTTCCTAC } \\
\text { R:CCCTGTAGCCATGCTGTTTT }\end{array}$ \\
\hline POU4F1 & $\begin{array}{l}\text { F: CGCGGACTTTCGGAGTGTTT } \\
\text { R:CAAAGTGAGGCTGCTTGCTG }\end{array}$ \\
\hline POU4F2 & $\begin{array}{l}\text { F: AAGCCTACTTTGCCATTC } \\
\text { R:GCTCCCTCTTCAGTCCTC }\end{array}$ \\
\hline MAP2 & $\begin{array}{l}\text { F: CTCGCACAGAGTTATCC } \\
\text { R:GCAGACCTACCACCAA }\end{array}$ \\
\hline ATOH7 & $\begin{array}{l}\text { F: TTTATTCGCATCATCAGACC } \\
\text { R:CAATCAACCCATTCACAAGA }\end{array}$ \\
\hline PAX6 & $\begin{array}{l}\text { F: AACGATAACATACCAAGCGTG } \\
\text { R:GGTCTGCCCGTTCAACATC }\end{array}$ \\
\hline SYP & $\begin{array}{l}\text { F: GGACATGGACGTGGTGAA } \\
\text { R:GGAGTAGAGGAAGGCAAACA }\end{array}$ \\
\hline TUBB3 & $\begin{array}{l}\text { F: CCGAAGCCAGCAGTGTCTAA } \\
\text { R:AGGCCTGGAGCTGCAATAAG }\end{array}$ \\
\hline$\beta$-actin & $\begin{array}{l}\text { F: CTCTGGCCGTACCACTGGC } \\
\text { R:GTGAAGCTGTAGCCGCGC }\end{array}$ \\
\hline
\end{tabular}

NES, nestin; CRX, cone-rod homeobox; PROM1, prominin 1; BMI1, BMI1 proto-oncogene; MKI67, marker of proliferation Ki-67; PRPH2, peripherin 2; opsin 1, long wave sensitive; RCVRN, recoverin; NEURO1, neuronal differentiation 1; GFAP, glial fibrillary acidic protein; ROM1, retinal outer segment membrane protein 1; POU4F, POU domain, class 4, transcription factor 1; MAP2, microtubule associated protein 2; ATOH7, atonal bHLH transcription factor 7; PAX6, paired box 6; SYP, synaptophysin; TUBB3, tubulin $\beta 3$ class III; PCR, polymerase chain reaction; $F$, forward; $R$, reverse. was electrophoresed on $10 \%$ sodium dodecyl sulfatepolyacrylamide gel electrophoresis (SDS-PAGE) gel and then transferred onto polyvinylidene difluoride membranes (Bio-Rad Laboratories, Inc., Hercules, CA, USA). The polyvinylidene difluoride membranes were blocked by $5 \%$ bovine serum albumin (Sigma-Aldrich; Merck KGaA) for $1 \mathrm{~h}$ at room temperature. Then the membranes were incubated with retinal neuron-specific primary antibodies (Table II) overnight at $4^{\circ} \mathrm{C}$. The horseradish peroxidase-conjugated secondary antibodies were applied to the membranes for $2 \mathrm{~h}$ at room temperature. $\beta$-actin served as the normalized protein. The bands were visualized by ECL chemiluminescence substrates (ECL Plus; PerkinElmer Inc., Waltham, MA, USA). The bands were quantified by ImageJ software (National Institutes of Health, Bethesda, MD, USA.)

Fluorescence-activated cell sorting analysis. Single RGLCs and W-RBCs were suspended with a fluorescence-activated cell sorting analysisbuffer(PBS, $0.5 \%$ BSA, 2 mMEDTA-2Na- $2 \mathrm{H}_{2} \mathrm{O}$ ). The FIX and PERM ${ }^{\text {TM }}$ Cell Permeabilization kit (Invitrogen; Thermo Fisher Scientific, Inc.) and indirect immunolabeling were applied for flow cytometry analysis according to the manufacturer's protocols. Briefly, RGLCs were incubated with POU class 4 homeobox 2 (Brn3b, 1:100) primary antibody for $15 \mathrm{~min}$ at $\mathrm{RT}$, and incubated with rabbit anti-fluorescein isothiocyanate-conjugated secondary antibody (1:300) (both from Abcam, Cambridge, UK) for $20 \mathrm{~min}$ at room temperature. The percentage of $\mathrm{Brn} 3 \mathrm{~b}^{+}$cells was detected by flow cytometry (fluorescence-activated cell sorter Aria; BD Biosciences, Franklin Lakes, NJ, USA).

Animals. The animal experiments were conducted in accordance with the ARVO Statement for the Use of Animals in Ophthalmic and Vision Research and approved by the Animal Experimental Ethical Inspection to Ethics Committee of Zhongshan Ophthalmic Center (Sun Yat-sen University). Adult nude mice of either gender (6-8 w, 15-20 g) (Laboratory Animal Center, Sun Yat-sen University) were housed in cases under a 12:12 h light-dark cycle with water and food provided ad libitum in the Laboratory Animal Center of Zhongshan Ophthalmic Center.

Tumorigenicity studies. The nude mice were anesthetized by intraperitoneal injections of a ketamine $(100 \mathrm{mg} / \mathrm{kg})$ and xylazine $(10 \mathrm{mg} / \mathrm{kg})$ cocktail. Then W-RBCs, RNLCs and RGLCs were respectively injected into one eye of 18 nude mice. Each cell type was also respectively injected into the anterior chamber (AC, 2 eyes), subretinal space (SRS, 2 eyes) and vitreous cavity (VC, 2 eyes). Cell suspensions ( $10^{5}$ cells $\left./ \mu \mathrm{l}\right)$ were injected into the $\mathrm{AC}(1 \mu \mathrm{l})$, SRS $(2 \mu \mathrm{l})$ or VC $(3 \mu \mathrm{l})$, as previously described (34). Changes in the eyeball were observed with a slit lamp. The mice were sacrificed 27 days following transplantation, and the eyeballs were collected for hematoxylin and eosin staining.

Immunofluorescence analysis. The suspended W-RBCs were seeded onto PDL-coated Fisher coverslips (Thermo Fisher Scientific, Inc.) for $1 \mathrm{~h}$ at $37^{\circ} \mathrm{C}$. W-RBCs, hRPCs, RNLCs and RGLCs were then subjected to immunolabeling, as previously reported (20). The images were captured with a confocal laser 
Table II. Antibodies used for immunofluorescence analysis and western-blot analysis.

\begin{tabular}{llcll}
\hline Antigen & Species & Dilution ${ }^{\mathrm{a}}$ & & Supplier details \\
\hline PAX6 & Mouse & $1: 100$ & Merck KGaA & Catalog no. \\
NES & Rabbit & $1: 50$ & Wuhan Boster Biological Technology, Ltd. & BA1285 \\
GFAP & Mouse & $1: 50 / 1: 200^{\mathrm{a}}$ & Abcam & Ab4648 \\
ISL1 & Rabbit & $1: 200$ & Abcam & Ab109517 \\
RHO & Mouse & $1: 100 / 2 \mu \mathrm{g} / \mathrm{ml}^{\mathrm{a}}$ & Abcam & Ab3267 \\
MAP2 & Mouse & $1: 100$ & Abcam & Ab11267 \\
SYP & Rabbit & $1: 250$ & Abcam & Ab52636 \\
Recoverin & Mouse & $1: 100$ & Abcam & Ab31928 \\
SSEA 4 & Mouse & $15 \mu \mathrm{g} / \mathrm{ml}^{2}$ & Abcam & Ab16287 \\
MKi 67 & Rabbit & $1: 100$ & Abcam & Ab16667 \\
OTX2 & Mouse & $1: 200 / 1: 500^{\mathrm{a}}$ & Abcam & Ab21990 \\
SOX2 & Rabbit & $1: 250$ & Abcam & Ab137385 \\
CRX & Mouse & $1: 200$ & Santa Cruz Biotechnology, Inc. & Sc377138 \\
Brn3b & Rabbit & $1: 100 / 0.2 \mu \mathrm{g} / \mathrm{ml}^{\mathrm{a}}$ & Abcam & Ab56026 \\
$\beta$-actin & Rabbit & $1: 1,000^{\mathrm{a}}$ & Cell Signaling Technology, Inc. & mAb4970 \\
\hline
\end{tabular}

Merck KGaA, Darmstadt, Germany; Wuhan Boster Biological Technology, Ltd., Wuhan, China; Abcam, Cambridge, UK; Santa Cruz Biotechnology, Inc., Dallas, TX, USA; Cell Signaling Technology, Inc., Danvers, MA, USA; PAX6, paired box 6; NES, nestin; GFAP, glial fibrillary acidic protein; ISL1, ISL LIM homeobox 1; RHO, rhodopsin; MAP2, microtubule associated protein 2; SYP, synaptophysin; MKi67, marker of proliferation Ki-67; OTX2, orthodenticle homeobox 2; SOX2, SRY-box 2; CRX, cone-rod homeobox. ${ }^{a}$ Dilution for western blot analysis.

scanning microscope (LSM 510) or fluorescence microscopy (Carl Zeiss AG, Oberkochen, Germany). The primary antibodies are detailed in Table II.

Statistical analysis. Each experiment was performed in triplicate. All data are represented as the mean \pm standard deviation. Significance was assessed with the Student's t-test for the comparison of two variables or with a two-way analysis of variance for multivariable comparisons using SPSS software (version 13.0; SPSS, Inc., Chicago, IL, USA). P<0.05 was considered to indicate a statistically significant difference.

\section{Results}

WERI-Rb-1 cells retained retinal progenitor cell properties. The data revealed a marked expression of the hRPC-related genes nestin $(N E S)$ and cone-rod homeobox $(C R X)$, but not paired box 6 (PAX6) in W-RBCs (Fig. 2A). Interestingly, expression of the ESC-specific gene prominin 1 (PROMI) and proliferative genes BMI1 proto-oncogene $(B M I-1)$ and marker of proliferation Ki-67 (MKI67), especially MKI67, was remarkably higher in W-RBCs than in hRPCs (Fig. 2A). In addition, W-RBCs and hRPCs expressed similar markers, with high expression of NES, CRX, SRY-box 2 (SOX2) and Ki-67, and low expression of glial fibrillary acidic protein (GFAP, an astrocyte marker). However, the expression of PAX6 was much lower in W-RBCs than in hRPCs (Fig. 2B). These findings implied the differentiation potential of retinal neurons and the high proliferation ability of W-RBCs.

Optimization of the regulated $W-R B C$ differentiation system. With regard to the generation of RNLCs, the results demonstrated progressively decreased expression of NES, an intermediate neurofilament of undifferentiated cells, in the twostep procedure (DL-20 d or N2-Neural-20d). The fold-change of the NES transcripts decreased to 0.328 after 10 -day priming with DL, and then further declined to 0.118 following the additional 10 days of differentiation. This trend was also observed in the group that underwent the two-step process without DL (N2-Neural-20d), but with a lower reduction in NES $(0.352$ after priming and 0.218 after differentiation). NES also declined significantly in cells cultured in the neural medium without DL for 10 days (Neural-10d). These findings suggested a gradual withdrawal of the progenitor characteristics of W-RBCs and an engagement into the differentiation process. In contrast, transcripts corresponding to retinal neurons, especially photoreceptors, were upregulated in differentiated W-RBCs. Specifically, the photoreceptor transcripts peripherin $2(P R P H 2)$ and recoverin were significantly increased after the two-step procedure plus DL (DL-20d). Notably, there was a much higher fold-change of opsin 1, long wave sensitive (OPN1LW, mature cone) in this group (DL-20d), whereas the remaining groups showed an obvious reduction. The neuralrelated transcript neuronal differentiation 1 (NEUROD1) also increased notably in the DL-20d group. In contrast, removal of DL caused a reduction in the retinal neuron-related transcript expression (Fig. 3A and B).

The direct incubation of W-RBCs in neural medium with (DL-Neural-10d) or without DL (Neural-10d) had a significantly weaker effect on RNLC differentiation, with just two transcripts, retinal outer segment membrane protein 1 (ROM1, photoreceptor) and GFAP, increasing in the DL group (DL-Neural-10d) and no effective increase in any related transcripts in the non-DL group (Neural-10d). Together, these results demonstrated that bFGF is necessary for the priming of W-RBCs into a pre-neuronal state and that DL promotes 


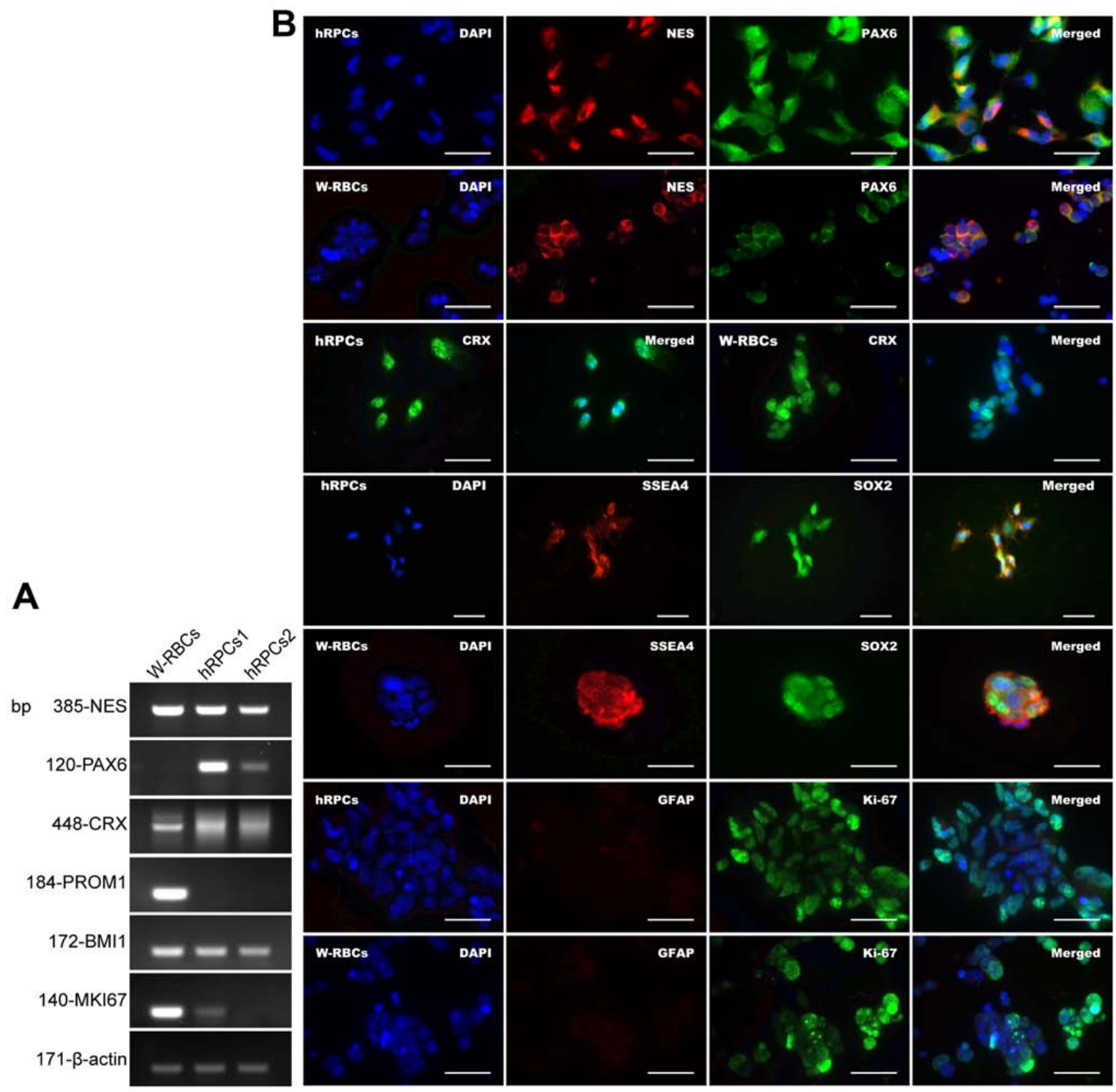

Figure 2. Retinal neuron differentiation potential of W-RBCs. (A) Reverse transcription-quantitative polymerase chain reaction revealed that the W-RBCs expressed RPC-specific genes, NES and $C R X$, similar to two controls (hRPCs1 and hRPCs2) obtained from two HENRs at the 8-9th week of gestation but not PAX6. The expression of pluripotency- and proliferation-related genes, including PROM1, BMI1 and MKI67, was also much higher in the W-RBCs than in the hRPCs. (B) Immunofluorescence confirmed that both the W-RBCs and hRPCs expressed similar RPC markers (NES and CRX) but the expression of PAX6 was weaker in the W-RBCs compared to the hRPCs. In addition, the W-RBCs and hRPCs stained positively for ESC markers (SSEA4 and SOX2) and the proliferative marker Ki-67 and negatively for the glia cell marker glial fibrillary acidic protein. Scale bar, $50 \mu \mathrm{m}$. W-RBCs, WERI-Rb-1 cells; RPCs, retinal progenitor cells; hRPCs, human retinal progenitor cells; NES, nestin; PAX6, paired box 6; CRX, cone-rod homeobox; PROM1, prominin 1; BMI1, BMI1 proto-oncogene; MKI67, marker of proliferation Ki-67; ESC, embryonic stem cell.

the differentiation of RNLCs, especially that of mature photoreceptor-like cells (PLCs) (Fig. 3A and B).

Given that RGCs are specified prior to photoreceptors during vertebrate retinogenesis, the RGC induction process was shortened to 10 days, with 20-day procedures used as controls. The expression of NES decreased significantly in all the induction samples, providing evidence of cellular differentiation into mature cells. PAX6 pathway-related genes, critical genes that directly activate the development of RGCs, and other RGC-related genes were upregulated in most samples. Specifically, $P A X 6$, an upstream gene of $A T O H 7$, was increased in all groups, but only two groups treated without the neural medium for 10 days presented a significant foldchange (DLN-N2-10d: 58; N2-TR-10d: 37) (Fig. 3E). The expression of $A T O H 7$, a key gene that regulates the fate of RGCs, was significantly high in the 10-day gene-transfected groups (DLNAD-10d: 236; DLNAD-Neural-10d: 694-fold change) (Fig. 3C and D), and high in the 20-day transfected and non-transfected groups, albeit with no statistical significance (Fig. 3C and D). The upregulation of PAX6 and ATOH7 also activated the downstream genes POU class 4 homeobox 1 and POU class 4 homeobox 2 . Specifically, cells cultured only 
A
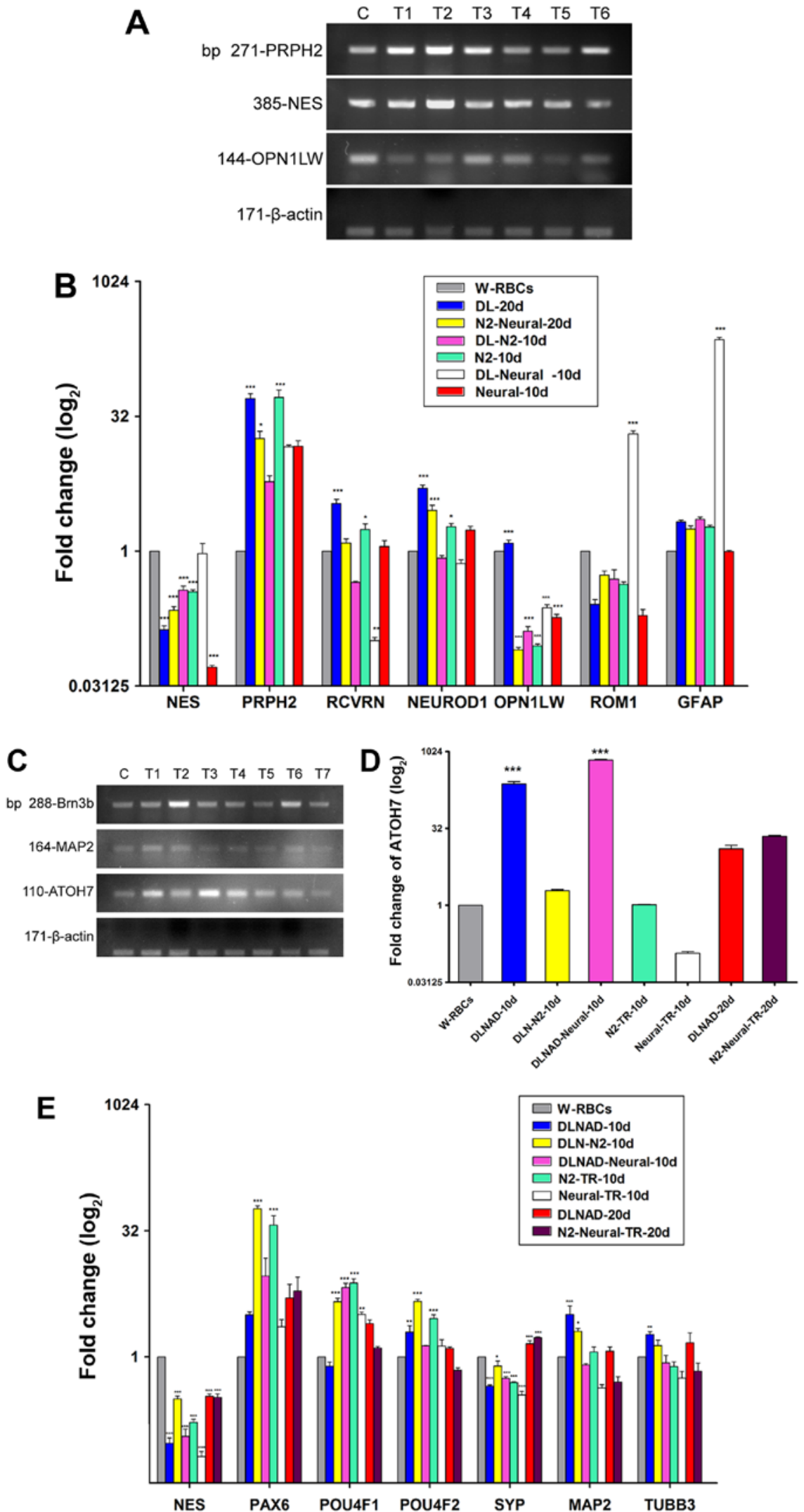

Figure 3. Optimization of retinal neuron-like cell differentiation system. (A and B) Different expressions of hRPC-related genes and photoreceptor-related genes among six RNLCs induction groups and W-RBCs tested by (A) RT-PCR and (B) qPCR. (C) RT-PCR analysis presented the expression of exogenous ATOH7 and retinal ganglion cell (RGC)-related genes among retinal ganglion-like cells induction groups and W-RBCs. (D) qPCR showed that ATOH7 markedly increased in gene transfected groups. (E) Real-time PCR revealed the hRPC- and RGC-related gene expressions among different induction samples and control (W-RBCs). Graphs present data are mean \pm standard error of the mean $(\mathrm{n}=3)$. ${ }^{*} \mathrm{P}<0.05$, ${ }^{* * *} \mathrm{P}<0.01$ and ${ }^{* * * *} \mathrm{P}<0.001$ vs. control. (A) $\mathrm{C}$, control (W-RBC); DL, Dkk-1 + Lefty-A; T1, DL-N2-10d; T2, DL-Neural-10d; T3, DL-20d; T4, N2-Neural-20d; T5, N2-10d T6, Neural-10d. (C) C, control (W-RBCs); T1, DLNAD-10d; T2, DLN-N2-10d; T3, DLNAD-Neural-10d; T4, DLNAD-20d; T5, N2-Neural-TR-20d; T6, N2-TR-10d; T7, Neural-TR-10d. PCR, polymerase chain reaction; RT, reverse transcription; hRPCs human retinal progenitor cells; W-RBCs, WERI-Rb-1 cells; qPCR, quantitative PCR; hRPC, human retinal progenitor cell; RNLCs, retinal neuron-like cells; RGC, retinal ganglion cell; ATOH7, atonal bHLH transcription factor 7. 

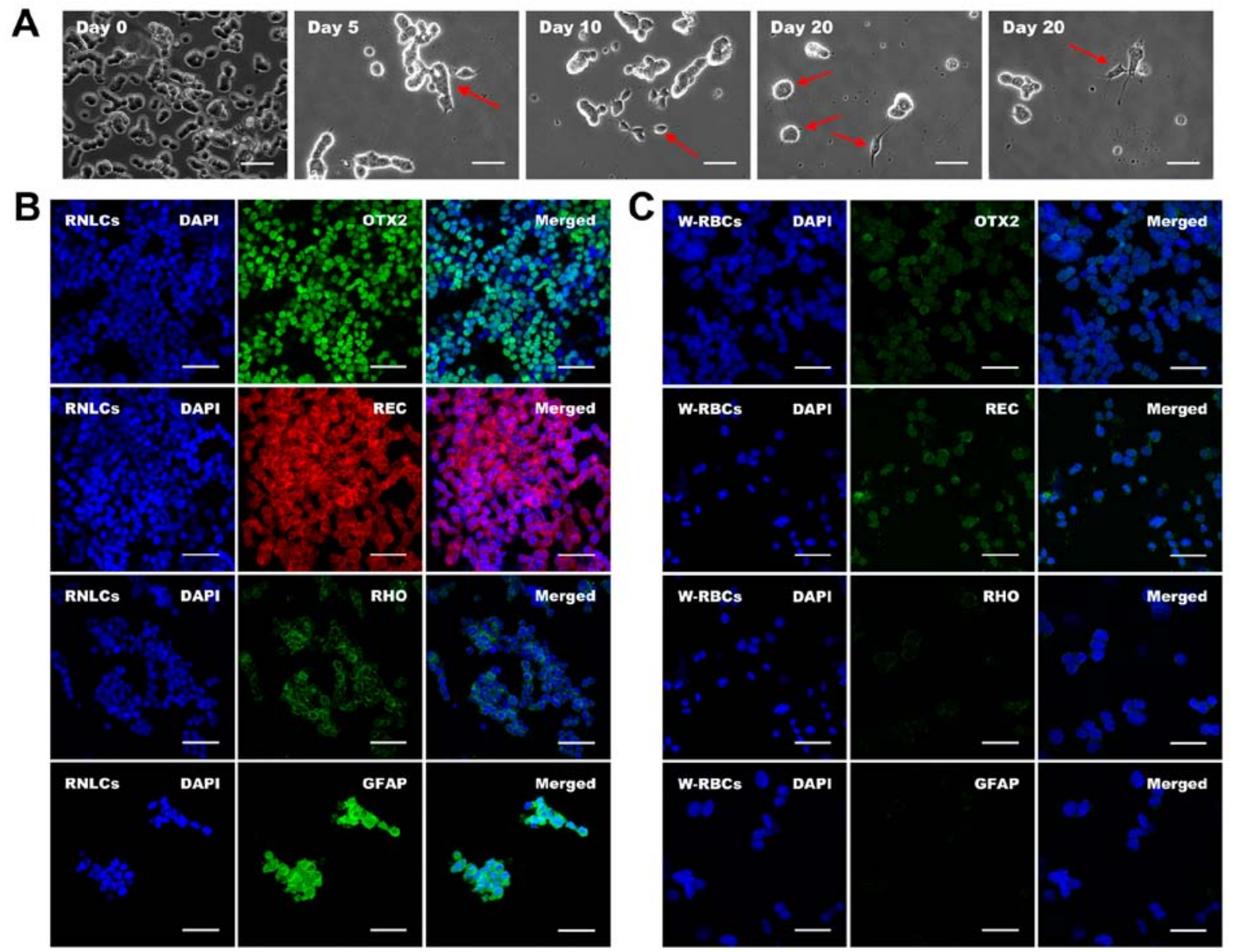

D

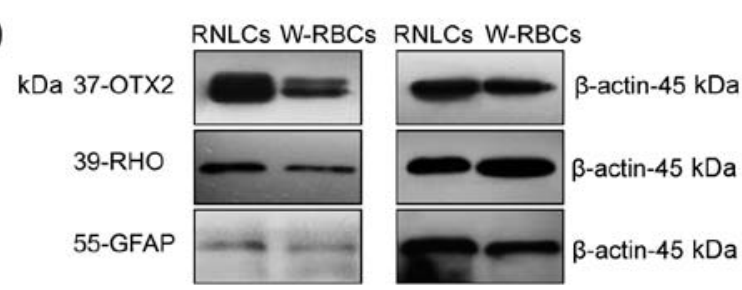

Figure 4. Differentiation of W-RBCs into RNLCs. (A) Morphological changes in the W-RBCs during differentiation. When cultured in the conditioned media, the W-RBCs gradually generated synapse-like and photoreceptor-like morphology from day 0 to 20 (see arrow). (B) Immunofluorescence indicated that the RNLCs expressed positive photoreceptor-related markers, including OTX2, REC and RHO, as well as the astrocyte maker GFAP, whereas (C) W-RBCs showed negative staining. (D) Western blot quantification revealed that the levels of the OTX2, RHO and GFAP proteins were much higher in two-step DL-induced sample (DL-20d) compared to those of the W-RBC control. Scale bar, $50 \mu \mathrm{m}$. W-RBCs, WERI-Rb-1 cells; RNLCs, retinal neuron-like cells; OTX2, orthodenticle homeobox 2; RHO, rhodopsin; GFAP, glial fibrillary acidic protein; DL, Dkk-1 + Lefty-A; RNLCs, retinal neuron-like cells .

in basic or neural media with/without DLN for 10 days all expressed much more Brn3a (RGC precursor), whereas those cultured in neural medium expressed less Brn3b (mature RGC) than those in basic medium. Interestingly, the two-step 10-day protocol (DLNAD-10d) downregulated Brn3a but significantly upregulated Brn3b and other mature RGC-related genes, including microtubule associated protein 2 (MAP2) and tubulin $\beta 3$ class III (TUBB3), which had a lower expression in the remaining groups (Fig. $3 \mathrm{C}$ and $\mathrm{E}$ ). The 20-day stepwise strategies (DLNAD-20d or N2-Neural-TR-20d) appeared to have a much weaker effect on the differentiation of RGLCs, with only synaptophysin (SYP, neural synapsis specific) showing a statistically significant increase (Fig. 3E). Collectively, the data confirmed that the 10-day strategies was superior to the 20-day strategies with regard to RGLC differentiation and that the one-step procedure with DLN could effectively induce mature RGLCs, even without gene transfection (DLN-N2-10d).

$W$-RBCs differentiated into RNLCs. The cells generated from the 20-day two-step procedure with the addition of DL (DL-20d) were further characterized. Spiculate features on cell clusters (Fig. 4A, day 5) were observed 5 days following W-RBC plating (Fig. 4A, day 0). By the end of priming on the tenth day, some cells developed smaller triangular or oval, short neurite features (Fig. 4A, day 10). Following completion of differentiation on day 20, PLCs were observed, with longer and branched neurite-like features (Fig. 4A, day 20). The immunofluorescence study indicated that RNLCs expressed markers of orthodenticle homeobox 2 (OTX2), REC, rhodopsin (RHO) and GFAP (Fig. 4B), which were much less expressed or absent in W-RBCs (Fig. 4C). The western blot assay confirmed that 

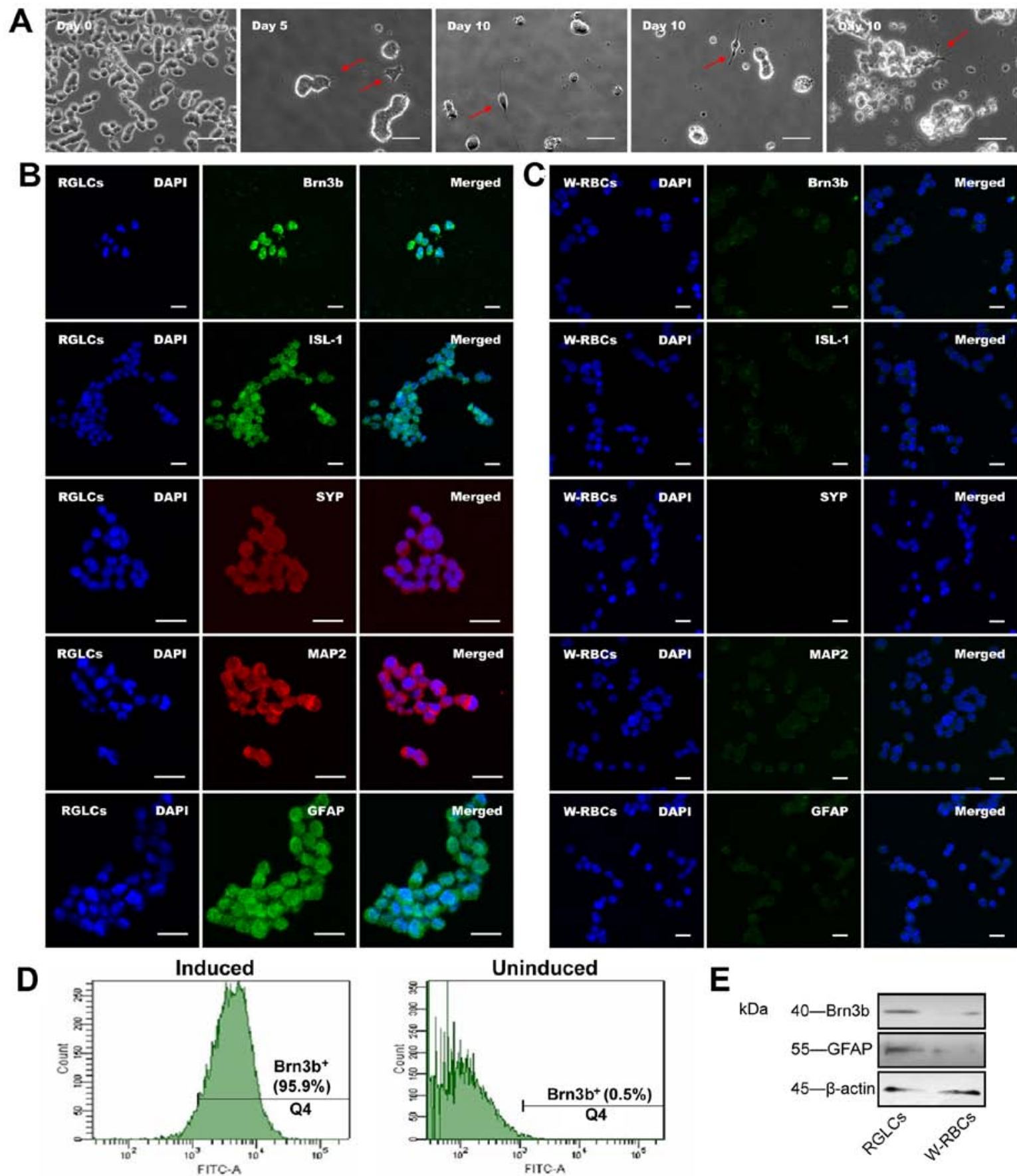

Figure 5. Differentiation of W-RBCs into RGLCs. (A) Morphological changes in the W-RBCs during differentiation. When transferred to conditioned media, the W-RBCs gradually developed retinal neuron-like and ganglion-like morphology from day 0 to 10 (see arrow). (B) The RGLCs presented positive immunofluorescence staining with Brn3b, ISL1, SYP, MAP2 and GFAP, whereas (C) W-RBCs showed negative staining. (D) Flow cytometry revealed that the percentage of $\mathrm{Brn}_{3} \mathrm{~b}^{+}$cells climbed to $95.9 \%$ after cell differentiation but remained at just $0.5 \%$ in the W-RBCs. (E) Western blot quantification confirmed that the expression of Brn3b and GFAP were higher in the induced group than in the non-induced group (W-RBCs). Scale bar, (A) $50 \mu \mathrm{m}$ and (B and C) $25 \mu \mathrm{m}$. W-RBCs, WERI-Rb-1 cells; RGLCs, retinal ganglion-like cells; ISL1, ISL LIM homeobox 1; SYP, synaptophysin; MAP2, microtubule associated protein 2; GFAP, glial fibrillary acidic protein.

the OTX2, RHO and GFAP proteins were remarkably upregulated in RNLCs (Fig. 4D). These results demonstrated that this procedure could effectively induce W-RBCs into RNLCs, and into PLCs and gliacytes in particular.

$W$-RBCs differentiated into RGLCs. The cells generated from the one-step priming with DLN (DLN-N2-10d) were further characterized through additional assays. Fig. 5A (day 0) shows W-RBCs attached to 6-well plates. On day 5, cells displayed a neuronal morphology, with short-branched neurite features (Fig. 5A, day 5). Following 10-day differentiation, cells displayed an RGC-like morphology, and a few showed a bipolar cell-like phenotype (Fig. 5A, day 10). Immunofluorescence confirmed that the RGLCs expressed Brn3b, ISL LIM homeobox 1 (-1, RGC), SYP, MAP2 and GFAP (Fig. 5B), whereas these markers were much less expressed or even absent in W-RBCs (Fig. 5C). Furthermore, a significant increase in the percentage of 

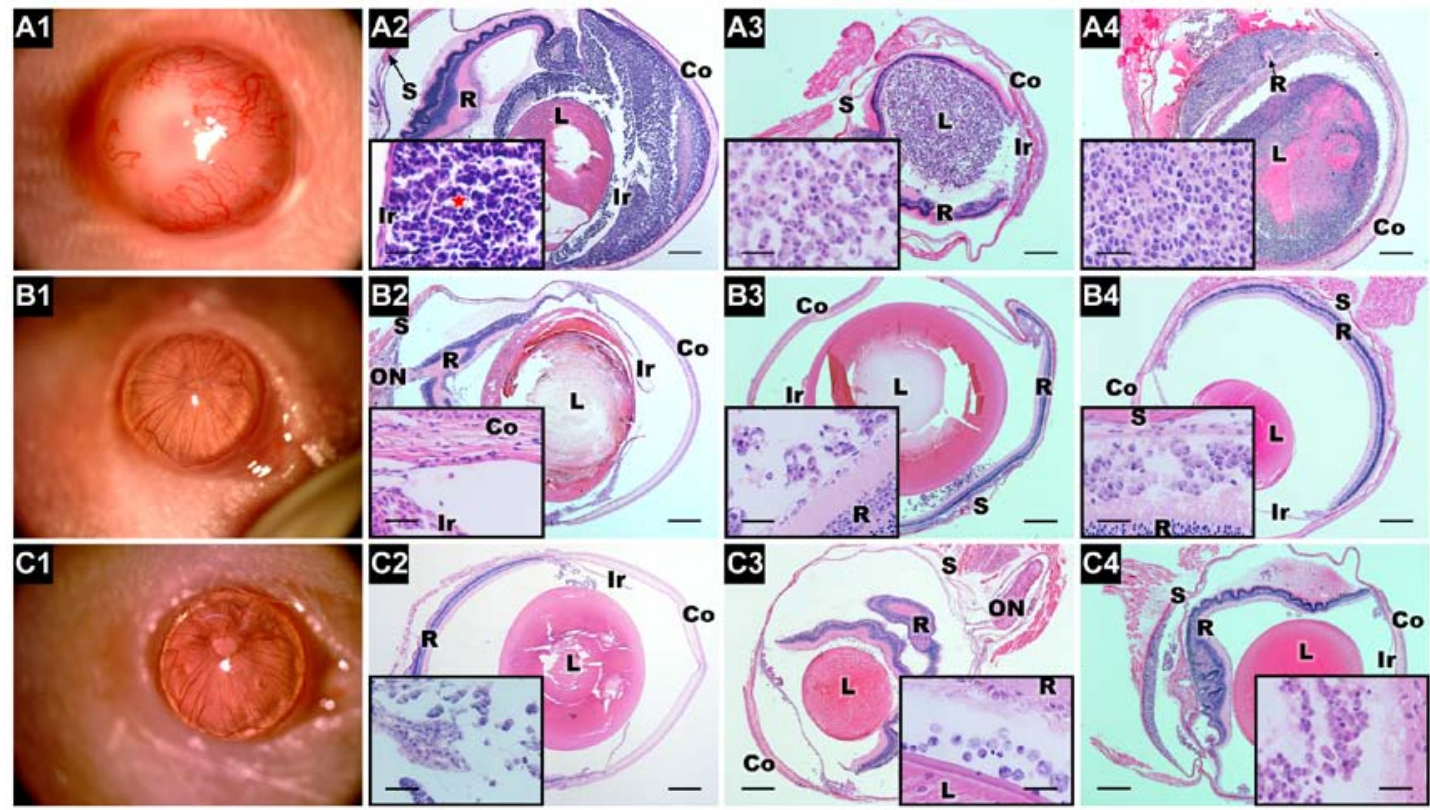

Figure 6. Tumorigenicity of the undifferentiated and the differentiated W-RBCs in vivo. (A1) At 25 days after injection into the AC, the W-RBCs developed a large tumor (slit lamp). (A2-A4) H\&E examination showed that the injected W-RBCs generated a significant tumor in the AC, VC and SRS. The tumor consisted of highly packed undifferentiated small rounded cells and exhibited several Homer-Wright rosettes (A2, see star). Notably, the xenograft tumor extended from the $\mathrm{AC}$ to the $\mathrm{VC}$ (A2). (B1 and $\mathrm{C} 1$ ) No tumor (slit lamp) was observed 27 days after injecting the (B1) RNLCs and (C1) RGLCs into the AC. (B2-B4 and C2-C4) Hematoxylin and eosin examination showed that grafted retinal neuron-like cells and retinal ganglion-like cells formed no significant tumor in the AC, VC or SRS. Scale bar, $500 \mu \mathrm{m}$. Magnification, $50 \mu \mathrm{m}$. Abbreviations, Co, cornea; Ir, iris: L, lens: R, retina; S, sclera; ON, optic nerve; W-RBCs, WERI-Rb-1 cells; AC, anterior chamber; VC, vitreous cavity; SRS, subretinal space; H\&E, hematoxylin and eosin; RNLCs, retinal neuron-like cells.

Brn3b $\mathrm{b}^{+}$cells $(95.9 \%)$ was observed in RGLCs compared to that in W-RBCs $(0.5 \%)$ (Fig. 5D). Western blot analysis indicated that Brn3b and GFAP protein levels were upregulated following cell differentiation (Fig. 5E). Accordingly, the onestep priming with DLN (DLN-N2-10d) effectively activated the differentiation of RGLCs.

Differentiated W-RBCs showed poor tumorigenicity in vivo. Undifferentiated and differentiated W-RBCs were injected into nude mice eyes to assess tumorigenicity. W-RBCs gave rise to significant tumors in six receptor eyes (100\%) (Fig. 6A1-4). Histopathological examination indicated that the xenografted tumors were composed of small, round cells, with scanty cytoplasm and hyperchromatic nuclei; Homer-Wright rosette structures were also observed (Fig. 6A2). Importantly, the AC xenograft tumor not only grew in the $\mathrm{AC}$ but also extended into the VC (Fig. 6A2). In contrast, all differentiated W-RBCs were located near the injection site and showed no significant proliferation in any of the eyes (Fig. 6B1-C4). Although the RNLCs/RGLCs injected in the AC migrated from the AC into the $\mathrm{VC}$, no significant proliferation was observed (Fig. 6B2 and C2). These results indicated that differentiation remarkably reduced the tumorigenesis potential of W-RBCs.

\section{Discussion}

$W-R B C$ s retain retinal neuron differentiation potency. The homozygous deletion of both $R B 1$ alleles in W-RBCs could revert cells to a progenitor-like status and exhibit more advanced neuroblastic differentiation potential compared to Y79 (12). Thus, W-RBCs were selected in the present study. The data indicated a link between W-RBCs and normal hRPCs with regards to gene expression and molecular markers, thus providing the impetus for W-RBCs to further differentiate into retinal neurons

W-RBCs differentiate into RNLCs. Some signals, such as Wnt and Nodal signals, are involved in both tumorigenesis and retinal development. In neoplastic stem cells, the canonical Wnt pathway acts as a mitogenic regulator of its embryonic function (24). The nodal family proteins give rise to the ectoderm and mesoderm (35), whereas neuroectoderm formation requires blocking of nodal signaling by DL (36). Moreover, there is cross-talk between Wnt and Nodal signals, they exert a synergistic effect via LEF and Smad transcripts. The authors previously adopted the DKK1 and Lefty-A, antagonists of Wnt and Nodal signaling, respectively, to induce retinal neurons from iPSCs (21) and from retinoblastoma stem cells (37). However, it has not been previously reported to use the Dkk-1 and Lefty-A to induce W-RBCs into retinal neurons.

Herein, six induction protocols were compared to identify an easy and effective method to harvest sufficient RNLCs, especially PLCs, from W-RBCs. The decreased rate of NES was shown to be hindered by bFGF priming but promoted by DL and by further B27 differentiation. Meanwhile, mature photoreceptor (PRPH2 and $R H O$ ) and neuronal (NEURODI) genes were significantly increased in groups treated by both bFGF and B27, especially through the addition of DL. Furthermore, OPNILW, another key gene regulating cone development, was only upregulated in the two-step procedure with DL (DL-20d). These results suggested that bFGF priming promotes the neuronal commitment potency of W-RBCs, which is consistent with previous studies $(22,23)$ and that DL and B27 further motivate photoreceptor and neuron differentiation. Nevertheless, some studies reported that bFGF 
does not affect RHO expression and even confines RPCs to glial cells instead of photoreceptors $(38,39)$. Herein, ROM1, expressing in the retinal outer segment, was significantly increased by direct treatment with DL and B27, without bFGF (DL-Neural-10d). However, this procedure also remarkably upregulated GFAP ( 229 -fold) and reported a poorer performance in promoting other photoreceptor genes as compared with bFGF priming. These results suggested that bFGF priming, together with DL and B27 differentiation, are all necessary to generate retinal neurons from W-RBCs.

W-RBCs differentiate into RGLCs. The development of RGCs in vertebrate retina occurs much earlier than photoreceptor development and is regulated by several critical signals and genes. ATOH7 is a key gene in RGC generation $(40,41)$. Targeted deletion of ATOH7 blocks terminal RGC differentiation (42). Contrarily, overexpression of $A T O H 7$ initiates RGCs from iPSCs (32), 293T and ND7 cells. Hes1 maintains RPC fate and inhibits $A T O H 7$ (32). PAX6, a critical upstream transcription factor, can motivate $A T O H 7$ by inhibiting Hes1 $(43,44)$. Moreover, suppression of Notch signaling could directly inhibit Hes1 and increase RGC production. Notch signaling can also inhibit canonical Wnt signaling (27), while Wnt and BMP signals antagonize each other (28). Co-suppression of Nodal, BMP, Wnt, Notch and activation of FGF signaling could benefit neural and eye-field specification $(21,37)$.

Thus, seven procedures using various supplements and induction periods have been designed to assess whether W-RBCs could initiate RGLCs in an earlier period, which is similar to the human RGC development timeline. Previous studies have suggested that the unique inhibition of Wnt and Nodal signaling is not sufficient for RGC differentiation in both iPSCs and retinoblastoma stem cells $(21,37)$. However, inhibition of BMP signaling by Noggin can upregulate PAX6 in ESCs $(45,46)$. Moreover, the synergistic action of DKK1, Noggin and DAPT (notch signaling inhibitor) together with ATOH7 gene overexpression induced iPSCs into RGCs. Herein, the transient transfection of ATOH7 significantly increase ATOH7 expression in short term (10 days); this effect, however, was much weaker in long term (20 days). Moreover, the 20-day procedures demonstrated a much weaker effect on upregulating RGC- $(B r n 3 a / B r n 3 b)$ and neuron-related genes (MAP2 and TUBB3) compared to most of the 10-day procedures. This likely resulted from transient transfection, thus it is possible that more RGCs would be generated when stable gene transfection was adopted. Interestingly, however, two 10-day groups (DLN-N2-10d and N2-TR-10d) without exogenous $A T O H 7$ exhibited remarkable upregulation of $P A X 6, B r n 3 a$ and $B r n 3 b$ compared with transfected samples, implying that $A T O H 7$ is not the only factor expanding RGLC production. Indeed, other factors, such as the induction period, possibly serve important roles, meaning that RGLCs are likely to appear in W-RBCs at an earlier stage compared to photoreceptors (20 days). Moreover, the onset of ATOH7 expression may be affected by the inactivated RB1 allele because the cell cycle exit regulator, RB transcriptional corepressor $1(R b 1)$, activates the $A T O H 7$ promoter in vivo (47). Additionally, given the significantly high expression of PAX6 in these two samples, it is possible that $P A X 6$ upregulated RGC-related genes through genes other than ATOH7. The present findings are consistent with recent studies concluding that $A T O H 7$ is not the only one essential for RGC specification (48); however, the exact mechanism needs to be confirmed by further studies.

Furthermore, the bFGF effect of RPC maintenance was also observed in the present study in relation to NES expression. The two-step group (DLNAD-10d) treated with both bFGF and B27 among the short-period induction groups expressed more $M A P 2$ and $T U B B 3$, but less RGC-specific genes. Conversely, the one-step processes, involving bFGF treatment only (DLN-N2-10d and N2-TR-10d), induced more $B r n 3 a$ and/or Brn3b expression, indicating that bFGF had a positive effect on RGC generation other than RPC maintenance, and that B27 was more likely to motivate general neural cell growth instead of RGLCs. Additionally, different signaling pathway inhibitors (DKK1, Lefty A, Noggin and DAPT) were applied for RGC differentiation. DLN, even without DAPT, was observed to induce a more mature RGC

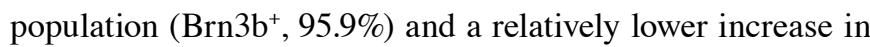
immature RGC gene expression ( $B r n 3 a)$. Thus, to the best of the authors' knowledge, the present study is the first to confirm that bFGF plus DLN could effectively promote mature RGC expansion in W-RBCs.

During the differentiation, however, the authors found that the RNLCs did not generate long neurite like other stem cells derived retinal neurons. That may result from the loss of $R b 1$ gene in W-RBCs. It was previously determined that the cell cycle exit regulator $R b l$ correlated with the critical retina development genes such as the ATOH7. The $R b 1$ gene could promote the $A T O H 7$ expression. The onset of $R b 1$ overlaps with the last mitosis in apically located RPCs at the onset of Ath 5 expression (49) and loss of $R b l$ has been reported to cause neuronal differentiation defects $(50,51)$.

Tumorigenicity of differentiated W-RBCs in vivo. Importantly, the differentiated W-RBCs presented much lower tumorigenicity, whereas undifferentiated W-RBCs generated considerable tumorigenesis in nude mice. These results provided convincing evidence that differentiation of W-RBCs inhibits their potential tumorigenesis, as previously observed in Y79 cells (52), thus indicating that W-RBCs could be transformed into poorly tumorigenetic RNLCs. This is consistent with the concept that malignant cells could transform into non-malignant cells after differentiation, as proposed by Pierce and Wallace (53) and Pierce (54). However, previous studies have revealed that retinoblastoma-derived horizontal cells could form metastatic tumors by re-entering the cell cycle $(55,56)$. Therefore, longterm observation should be considered for further assessment.

The present study comprehensively regulate critical cell signals to suggest facile and safe strategies to transform W-RBCs into different types of retinal neurons with low tumorigenicity. These results imply that differentiation therapy may be a promising candidate to reverse malignant retinoblastoma to a lower grade lesion with weaker aggressiveness, and at least to transform a fatal tumor to one more amenable to conventional therapies.

\section{Acknowledgements}

The present study was supported by the National Natural Science Foundation of China (grant nos. 81371007, 81430009 and 81170846). 


\section{References}

1. Bishop JO and Madson EC: Retinoblastoma. Review of the current status. Surv Ophthalmol 19: 342-366, 1975.

2. Chintagumpala M, Chevez-Barrios P, Paysse EA, Plon SE and Hurwitz R: Retinoblastoma: Review of current management. Oncologist 12: 1237-1246, 2007.

3. Degos L: All trans retinoic acid as a targeting drug for differentiation therapy in acute promyelocytic leukemia. Cancer Treat Res 64: 1-13, 1993.

4. Peterlin P, Garnier A,Tissot A, Garandeau C,Houreau-LanglardD, Hourmant M, Vantyghem S, Bonnet A, Guillaume T, Béné MC et al: Successful treatment of acute promyelocytic leukemia with arsenic trioxide and all-trans retinoic acid in a double lung and kidney transplanted patient. Ann Hematol 95: 1737-1738, 2016.

5. Kyritsis AP, Tsokos M, Triche TJ and Chader GJ: Retinoblastoma: A primitive tumor with multipotential characteristics. Invest Ophthalmol Vis Sci 27: 1760-1764, 1986.

6. Seigel GM: Differentiation potential of human retinoblastoma cells. Curr Pharm Biotechnol 12: 213-216, 2011.

7. Moore LH: Spontaneous regression of retinoblastoma. Br J Ophthalmol 50: 110, 1966.

8. Khodadoust AA, Roozitalab HM, Smith RE and Green WR: Spontaneous regression of retinoblastoma. Surv Ophthalmol 21: 467-478, 1977.

9. Mao J, Sun X, Tian Y, Li L, Li B, Ding H and Xing H: A molecular pathologic study on apoptosis in retinoblastoma and the mechanism of spontaneous regression in retinoblastoma. Zhonghua Yan Ke Za Zhi 32: 405-416, 1996 (In Chinese).

10. Xu X, Li B, Wang Y, Gao F and Zhang Z: Retinoblastoma spontaneous regression: Clinical and histopathologic analysis Zhonghua Yan Ke Za Zhi 50: 729-732, 2014 (In Chinese).

11. Challis GB and Stam HJ: The spontaneous regression of cancer. A review of cases from 1900 to 1987. Acta Oncol 29: 545-550, 1990.

12. Herman MM, Perentes E, Katsetos CD, Darcel F, Frankfurter A Collins VP, Donoso LA, Eng LF, Marangos PJ, Wiechmann AF, et al: Neuroblastic differentiation potential of the human retinoblastoma cell lines Y-79 and WERI-Rb1 maintained in an organ culture system. An immunohistochemical, electron microscopic, and biochemical study. Am J Pathol 134: 115-132, 1989.

13. Khanna H, Akimoto M, Siffroi-Fernandez S, Friedman JS Hicks D and Swaroop A: Retinoic acid regulates the expression of photoreceptor transcription factor NRL. J Biol Chem 281: 27327-27334, 2006

14. Saurat JH: Side effects of systemic retinoids and their clinical management. J Am Acad Dermatol 27: S23-S28, 1992.

15. Fraunfelder FW and FraunfelderFT: Adverse oculardrug reactions recently identified by the National Registry of Drug-Induced Ocular Side Effects. Ophthalmology 111: 1275-1279, 2004.

16. Hughes MF: Arsenic toxicity and potential mechanisms of action. Toxicol Lett 133: 1-16, 2002.

17. Trinh E, Lazzerini Denchi E and Helin K: Naturally deathresistant precursor cells revealed as the origin of retinoblastoma Cancer Cell 5: 513-515, 2004.

18. Ikeda H, Osakada F, Watanabe K, Mizuseki K, Haraguchi T, Miyoshi H, Kamiya D, Honda Y, Sasai N, Yoshimura N, et al: Generation of $\mathrm{Rx}^{+} / \mathrm{Pax}^{+}$neural retinal precursors from embryonic stem cells. Proc Natl Acad Sci USA 102: 11331-11336, 2005.

19. Lamba DA, Karl MO, Ware CB and Reh TA: Efficient generation of retinal progenitor cells from human embryonic stem cells. Proc Natl Acad Sci USA 103: 12769-12774, 2006.

20. Osakada F, Ikeda H, Mandai M, Wataya T, Watanabe K, Yoshimura N, Akaike A, Sasai Y and Takahashi M: Toward the generation of rod and cone photoreceptors from mouse, monkey and human embryonic stem cells. Nat Biotechnol 26: 215-224, 2008

21. Chen M, Chen Q, Sun X, Shen W, Liu B, Zhong X, Leng Y, Li C, Zhang W, Chai $\mathrm{F}$, et al: Generation of retinal ganglion-like cells from reprogrammed mouse fibroblasts. Invest Ophthalmol Vis Sci 51: 5970-5978, 2010.

22. Merhi-Soussi F, Angénieux B, Canola K, Kostic C, Tekaya M, Hornfeld D and Arsenijevic Y: High yield of cells committed to the photoreceptor fate from expanded mouse retinal stem cells. Stem Cells 24: 2060-2070, 2006.

23. Wu P, Tarasenko YI, Gu Y, Huang LY, Coggeshall RE and Yu Y: Region-specific generation of cholinergic neurons from fetal human neural stem cells grafted in adult rat. Nat Neurosci 5: $1271-1278,2002$
24. Silva AK, Yi H, Hayes SH, Seigel GM and Hackam AS: Lithium chloride regulates the proliferation of stem-like cells in retinoblastoma cell lines: a potential role for the canonical Wnt signaling pathway. Mol Vis 16: 36-45, 2010.

25. Denayer T, Locker M, Borday C, Deroo T, Janssens S, Hecht A, van Roy F, Perron M and Vleminckx K: Canonical Wnt signaling controls proliferation of retinal stem/progenitor cells in postembryonic Xenopus eyes. Stem Cells 26: 2063-2074, 2008.

26. Fuhrmann S: Wnt signaling in eye organogenesis. Organogenesis 4 : 60-67, 2008.

27. Xiao W, Chen X and He M: Inhibition of the Jagged/Notch pathway inhibits retinoblastoma cell proliferation via suppressing the PI3K/Akt, Src, p38MAPK and $\mathrm{Wnt} / \beta$ catenin signaling pathways. Mol Med Rep 10: 453-458, 2014

28. Haubold M, Weise A, Stephan H and Dünker N: Bone morphogenetic protein 4 (BMP4) signaling in retinoblastoma cells. Int J Biol Sci 6 700-715, 2010.

29. Kimchi A, Wang XF, Weinberg RA, Cheifetz S and Massagué J: Absence of TGF-beta receptors and growth inhibitory responses in retinoblastoma cells. Science 240: 196-199, 1988.

30. Klassen H, Ziaeian B, Kirov II, Young MJ and Schwartz PH: Isolation of retinal progenitor cells from post-mortem human tissue and comparison with autologous brain progenitors. J Neurosci Res 77: 334-343, 2004.

31. Schmitt S, Aftab U, Jiang C, Redenti S, Klassen H, Miljan E, Sinden $\mathbf{J}$ and Young M: Molecular characterization of human retinal progenitor cells. Invest Ophthalmol Vis Sci 50: 5901-5908, 2009.

32. Parameswaran S, Balasubramanian S, Babai N, Qiu F, Eudy JD, Thoreson WB and Ahmad I: Induced pluripotent stem cells generate both retinal ganglion cells and photoreceptors: Therapeutic implications in degenerative changes in glaucoma and age-related macular degeneration. Stem Cells 28: 695-703, 2010.

33. Livak KJ and Schmittgen TD: Analysis of relative gene expression data using real-time quantitative PCR and the 2(-Delta Delta C(T)) method. Methods 25: 402-408, 2001.

34. Chen P, Hu H, Chen Z, Cai X, Zhang Z, Yang Y, Yu N, Zhang J, $\mathrm{Xia} \mathrm{L}, \mathrm{Ge} \mathrm{J}$, et al: BRCA1 silencing is associated with failure of DNA repairing in retinal neurocytes. PLoS One 9: e99371, 2014

35. Vallier L, Reynolds D and Pedersen RA: Nodal inhibits differentiation of human embryonic stem cells along the neuroectodermal default pathway. Dev Biol 275: 403-421, 2004

36. Smith JR, Vallier L, Lupo G, Alexander M, Harris WA and Pedersen RA: Inhibition of Activin/Nodal signaling promotes specification of human embryonic stem cells into neuroectoderm. Dev Biol 313: 107-117, 2008.

37. Hu H, Deng F, Liu Y, Chen M, Zhang X, Sun X, Dong Z, Liu X and Ge J: Characterization and retinal neuron differentiation of WERI-Rb1 cancer stem cells. Mol Vis 18: 2388-2397, 2012

38. Zhao S and Barnstable CJ: Differential effects of bFGF on development of the rat retina. Brain Res 723: 169-176, 1996.

39. Czekaj M, Haas J, Gebhardt M, Müller-Reichert T, Humphries P, Farrar J, Bartsch U and Ader M: In vitro expanded stem cells from the developing retina fail to generate photoreceptors but differentiate into myelinating oligodendrocytes. PLoS One 7: e41798, 2012.

40. Brown NL, Patel S, Brzezinski J and Glaser T: Math5 is required for retinal ganglion cell and optic nerve formation. Development 128: 2497-2508, 2001

41. Liu W, Mo Z and Xiang M: The Ath5 proneural genes function upstream of Brn3 POU domain transcription factor genes to promote retinal ganglion cell development. Proc Natl Acad Sci USA 98: 1649-1654, 2001

42. Wang SW, Kim BS, Ding K, Wang H, Sun D, Johnson RL, Klein WH and Gan L: Requirement for math5 in the development of retinal ganglion cells. Genes Dev 15: 24-29, 2001

43. Riesenberg AN, Liu Z, Kopan R and Brown NL: Rbpj cell autonomous regulation of retinal ganglion cell and cone photoreceptor fates in the mouse retina. J Neurosci 29: 12865-12877, 2009.

44. Kayama M, Kurokawa MS, Ueda Y, Ueno H, Kumagai Y, Chiba S, Takada E, Ueno S, Tadokoro M and Suzuki N: Transfection with pax6 gene of mouse embryonic stem cells and subsequent cell cloning induced retinal neuron progenitors, including retinal ganglion cell-like cells, in vitro. Ophthalmic Res 43: 79-91, 2010.

45. Pera MF, Andrade J, Houssami S, Reubinoff B, Trounson A, Stanley EG, Ward-van Oostwaard D and Mummery C: Regulation of human embryonic stem cell differentiation by BMP-2 and its antagonist noggin. J Cell Sci 117: 1269-1280, 2004. 
46. Ying QL, Nichols J, Chambers I and Smith A: BMP induction of Id proteins suppresses differentiation and sustains embryonic stem cell self-renewal in collaboration with STAT3. Cell 115: 281-292, 2003

47. Ghiasvand NM, Rudolph DD, Mashayekhi M, Brzezinski JA IV, Goldman D and Glaser T: Deletion of a remote enhancer near ATOH7 disrupts retinal neurogenesis, causing NCRNA disease. Nat Neurosci 14: 578-586, 2011.

48. Yang Z, Ding K, Pan L, Deng M and Gan L: Math5 determines the competence state of retinal ganglion cell progenitors. Dev Biol 264: 240-254, 2003.

49. Kay JN, Link BA and Baier H: Staggered cell-intrinsic timing of ath5 expression underlies the wave of ganglion cell neurogenesis in the zebrafish retina. Development 132: 2573-2585, 2005.

50. Chen D, Opavsky R, Pacal M, Tanimoto N, Wenzel P, Seeliger MW, Leone $\mathrm{G}$ and Bremner R: Rb-mediated neuronal differentiation through cell-cycle-independent regulation of E2f3a. PLoS Biol 5: e179, 2007.

51. Souren M, Martinez-Morales JR, Makri P, Wittbrodt B and Wittbrodt J: A global survey identifies novel upstream components of the Ath5 neurogenic network. Genome Biol 10: R92, 2009.
52. del Cerro M, Notter MF, Seigel G, Lazar E, Chader G and del Cerro C: Intraretinal xenografts of differentiated human retinoblastoma cells integrate with the host retina. Brain Res 583: 12-22, 1992.

53. Pierce GB and Wallace C: Differentiation of malignant to benign cells. Cancer Res 31: 127-134, 1971.

54. Pierce GB: The cancer cell and its control by the embryo. Rous-Whipple Award lecture. Am J Pathol 113: 117-124, 1983.

55. Ajioka I, Martins RA, Bayazitov IT, Donovan S, Johnson DA, Frase S, Cicero SA, Boyd K, Zakharenko SS and Dyer MA: Differentiated horizontal interneurons clonally expand to form metastatic retinoblastoma in mice. Cell 131: 378-390, 2007.

56. Seigel GM, Tombran-Tink J,Becerra SP, Chader GJ, Diloreto DA Jr, del Cerro C, Lazar ES and del Cerro M: Differentiation of Y79 retinoblastoma cells with pigment epithelial-derived factor and interphotoreceptor matrix wash: Effects on tumorigenicity. Growth Factors 10: 289-297, 1994. 